\title{
A Scoping Review of Arts-Based Mindfulness Interventions for Children and Youth
}

\author{
Diana Coholic ${ }^{1} \cdot$ Nicholas Schwabe $^{1} \cdot$ Kenneth Lander $^{1}$
}

Published online: 16 March 2020

(c) The Author(s) 2020

\begin{abstract}
Mindfulness-Based Interventions (MBIs) hold promise for building resilience in children/youth. We were interested in understanding why some MBIs incorporate arts-based methods, and what key findings were identified from the study of these MBIs. We used a scoping review to address our research questions. Scoping reviews can help us better understand how different types of evidence can inform practice, policy, and research. Steps include identifying research questions and relevant studies, selecting studies for analysis, charting data, and summarizing results. We identified 27 research articles for analysis. MBIs included the use of drawing, painting, sculpting, drama, music, poetry, and karate. Rationales included both the characteristics of children/youth, and the benefits of the methods. Arts-based MBIs may be more relevant and engaging especially for youth with serious challenges. Specific focus should be paid to better understanding the development and benefits of these MBIs.
\end{abstract}

Keywords Mindfulness $\cdot$ Arts-based $\cdot$ Youth $\cdot$ Scoping review

Mindfulness is a holistic philosophy and way of being in the world, and it can be both a state (an experience) and a trait (a personality characteristic or disposition) (Kabat-Zinn, 2003). Mindfulness-Based Interventions (MBIs) can help people learn to focus their attention, and with regular practice, they can learn to be aware of their present thoughts, feelings, and bodily sensations without negative judgements (Kabat-Zinn, 1990). With this nonjudgmental awareness, an individual can develop the ability to choose a response to distressing situations and emotions instead of reacting with unhealthy behaviors and interpretations (Horesh \& Gordon, 2018). Indeed, emotion regulation is an important component in treating a variety of complex mental health challenges including anxiety (Chambers, Gullone, \& Allen, 2009). As a way of being in the world, mindfulness represents an innerresource that contributes to resilience, which is the ability to recover from tumultuous circumstances (Bajaj \& Pande, 2016). Thus, youth facing a variety of psychosocial stressors may find mindfulness a helpful strategy for mitigating challenges and building resilience.

Diana Coholic

dcoholic@laurentian.ca

1 School of Social Work, Laurentian University, Sudbury, ON P3E 2C6, Canada
MBIs have been developed for a range of conditions in both clinical and healthy adult populations. Well established MBIs include Mindfulness Based Stress Reduction (MBSR) (Kabat-Zinn, 1990), Mindfulness Based Cognitive Therapy (MBCT) (Segal, Williams, \& Teasdale, 2002), and Acceptance and Commitment Therapy (ACT) (Hayes, Strosahl, \& Wilson, 1999). There is evidence that MBSR improves mental health and reduces symptoms of stress, anxiety and depression, and MBCT prevents depressive relapse (Fjorback, Arendt, Ornbol, Fink, \& Walach, 2011). MBIs have also been found to be helpful in reducing symptoms of anxiety (Vollestad, Birkeland Nielsen, \& Hostmark Nielsen, 2012). ACT combines mindfulness and cognitive therapy with an emphasis on treating anxiety and depression but is typically delivered in a traditional one-on-one counselling setting. Most other MBIs are facilitated via group delivery making them cost-effective, and providing the additional benefit of developing social competencies (Klatt, Buckworth, \& Malarkey, 2009).

A wide variety of MBIs, often adapted from programs developed for adults, have also been investigated for use with children and youth in clinical settings and in schools with promising results. It appears that MBIs in schools may improve resilience (Zenner, Herrnleben-Kurz, \& Walach, 2014). Others have found that youth with serious 
mental health challenges who participated in MBSR developed improved attention and mood, self-concept, and interpersonal relationships (Van Vliet et al., 2017). A review of the evidence for MBCT for improving selfregulation in teenagers indicated that youths reported better self-regulation and coping (Perry-Parrish, CopelandLinder, Webb, Shields, \& Sibinga, 2016). Similarly, a review of MBIs for youth with anxiety reported that MBIs are effective for the treatment of anxiety disorders in youth (Borquist-Conlon, Maynard, Esposito Brendel, \& Farina, 2017).

Tan and Martin (2013) summarized the mechanisms that are thought to contribute to the effectiveness of practicing mindfulness. These include improved attentional capacity, which is important in learning processes; increased self-awareness and the ability to notice thoughts as transitory experiences that are not necessarily true (flexible thinking); and reduced distress and/or distress tolerance through the process of accepting thoughts and feelings rather than repressing or trying to control them. These mechanisms of change and consequent benefits can build on each other. For example, with improved attention and focus, self-awareness can be developed so that a youth can understand and express their feelings. With improved emotion regulation, they can cope better with challenges, which can affect overall mood and self-esteem (Coholic et al., 2019). However, this is a developing field and some have argued that findings should be considered tentatively promising (Zenner et al., 2014), while others argued that we need more research that examines the mechanisms of change that participants experience and/or self-report (Alsubaie et al., 2017; Chiesa, Fazia, Bernardinelli, \& Morandi, 2017), that is, learning mindfulness may not be the only factor implicated in change.

When MBIs are adapted from adult programs for use with children and youth, modifications are often made to make the programs more relevant for young people, for example, shortened meditation exercises and the addition of experiential activities, but typically, the structure of the program adheres to the original adult program. Some researchers have argued that there is a need to better understand the factors contributing to changes in children's behaviours, feelings, and thoughts as a result of having participated in an MBI (Harnett \& Dawe, 2012). In our own work, we have found that the enjoyment created through the use of arts-based methods engages our target population and is consistently reported as one of the most favorite aspects of our arts-based MBI (Coholic \& Eys, 2016). Thus, we were interested in better understanding what research exploring arts-based MBIs has been completed and why arts-based approaches were used by researchers and facilitators. With this information, future areas for research and practice can be identified.

\section{Scoping Reviews}

Scoping reviews have been successfully used to aid in the design of research, inform best policies/practices, and locate research gaps in the literature (Pham et al., 2014). Various definitions have been proposed to describe scoping reviews including to identify key concepts and sources of available evidence (Arksey \& O'Malley, 2005); to synthesize and analyze diverse research and non-research material (Davis, Drey, \& Gould, 2009); and to map the literature on a specific topic so that we can better understand how different types of evidence can inform practice, policy making, and research (Pham et al., 2014). Scoping reviews are most commonly used to rapidly develop a description and analysis of available literature in a specific area (Grant \& Booth, 2009). Study quality is not assessed, thus, more studies tend to be included compared to systematic reviews/meta-analyses. Therefore, the scoping review was selected as a methodology well suited to quickly, and with limited resources, map the emerging literature with regards to the use of arts-based group MBIs with children and youth. In a scoping review of scoping reviews, Pham et al. (2014) indicated that Arksey and O'Malley's (2005) framework was the most common methodological framework employed. We also used their five-stage framework to guide our work with the following steps: (1) identifying research questions, (2) identifying relevant studies, (3) study selection, (4) charting the data, and (5) collating and summarizing. Consultation is listed as an optional component (Arksey \& O'Malley, 2005).

\section{Method}

\section{Research Questions}

We were interested in exploring the existent research pertaining to arts-based group MBIs with children and youth aged 8-18 years old. The research questions were: (1) What are the MBIs that primarily use arts-based methods to facilitate mindfulness with children and youth? (2) Why do these MBIs focus on using arts-based methods? and (3) What are the key findings from these programs?

\section{Selection Criteria}

We focused on research published from 2000-2017 because studying MBIs with children and youth is an emergent area of research, and beginning with the year 2000 ensured a comprehensive search. Literature published in English was the focus as we did not have the resources to translate papers written in other languages. Criteria was also related 
to type of intervention including MBIs with children and youth aged 8-18 years old including all types of challenges and rationales for participation in the MBI; group delivery; and any group size and mix of genders. Importantly, for the purposes of our review, the MBI had to have a major focus on arts-based methods. We understood arts-based methods to include a variety of creative and experiential approaches such as drawing, painting, sculpting, games, movement such as karate or tai chi, drama, music, and poetry/journaling. We agreed that the MBIs had to be primarily focused around teaching mindfulness-based practices and concepts by way of arts-based activities so that arts-based activities were facilitated in every session serving as the context for the delivery of the mindfulness-based practices. We included all cultures, practitioner-types, and geographical/physical locations.

\section{Identifying Relevant Studies}

As academic journals are increasingly web-based we decided to conserve our limited resources by solely searching electronic databases. Our search was limited to English language articles published between January 2000 and March 2017. To identify relevant studies a number of search terms were selected in consultation with one of our university's librarians and based on the research questions. For instance, an article's abstract or title would require the term mindfulness and synonyms for children/youth, groups, and arts-based/ creative interventions. These terms were separated by
Boolean operator 'AND,' whilst synonyms were separated by 'OR.' Terms with varying suffixes were truncated with the asterisk symbol to yield more studies. The terms were then used to search the abstracts and titles of articles in their respective databases (see Table 1 for list of keyword search terms). The second and third authors, who were senior social work students training in the first author's research program, independently searched 22 databases which were expected to yield the most relevant results using the same set of search terms (see Table 2 for a list of the databases searched).

\section{Study Selection}

The initial search yielded 4363 articles. This number was reduced when 2116 duplicates were removed. The second and third authors then independently reviewed the titles and abstracts to identify articles that did not meet the inclusion criteria; this eliminated an additional 1365 articles. Another 674 articles were eliminated following the abstract review leaving 208 articles. The description of interventions in the remaining articles were then independently reviewed by the second and third authors to assess whether the interventions met the inclusion criteria. When there was a lack of consensus between these two authors, discussions were held with the first author regarding the inclusion of an article in order to resolve the discrepancies. The flow chart in Fig. 1 depicts the process of searching and screening the articles. Additionally, we found that our search yielded several dissertations but they were eliminated during the intervention description

Table 1 Database keyword search terms

Search terms and Boolean operators

(mindfulness) AND (youth* OR teen* OR child* OR laten* OR adolescen* OR kid* OR boy* OR girl* OR juvenile* OR minor* OR young* OR preteen* OR pubescent* OR prepubescent* OR junior* OR student* OR immature*) AND (program* OR creativ* OR art* OR activit* OR non-traditional* OR recreation* OR experiential* OR expressi* OR adventur* OR outdoor* OR play*) AND (group* OR class* OR club* OR circle* OR team* OR program* OR company* OR cast* OR gang* OR band* OR squad* OR crew* OR clan* OR collectiv* OR troop*)

Table 2 Databases searched

\begin{tabular}{ll}
\hline Databases & \\
\hline Academic OneFile & PsycINFO \\
CINAHL & PubMed \\
Directory of Open Access Journals & REHABDATA \\
JSTOR & Sage Journals \\
Literature Resource Center & Scholars Portal \\
Medline (Ovid) & ScienceDirect \\
Native Health Database & Social Work Abstracts \\
OVID Nursing Journals & Sociological Abstracts \\
Published International Literature on Traumatic Stress & Springer LINK \\
Project MUSE & Taylor \& Francis Online \\
ProQuest Nursing \& Allied Health Source & Wiley Online Library \\
\hline
\end{tabular}




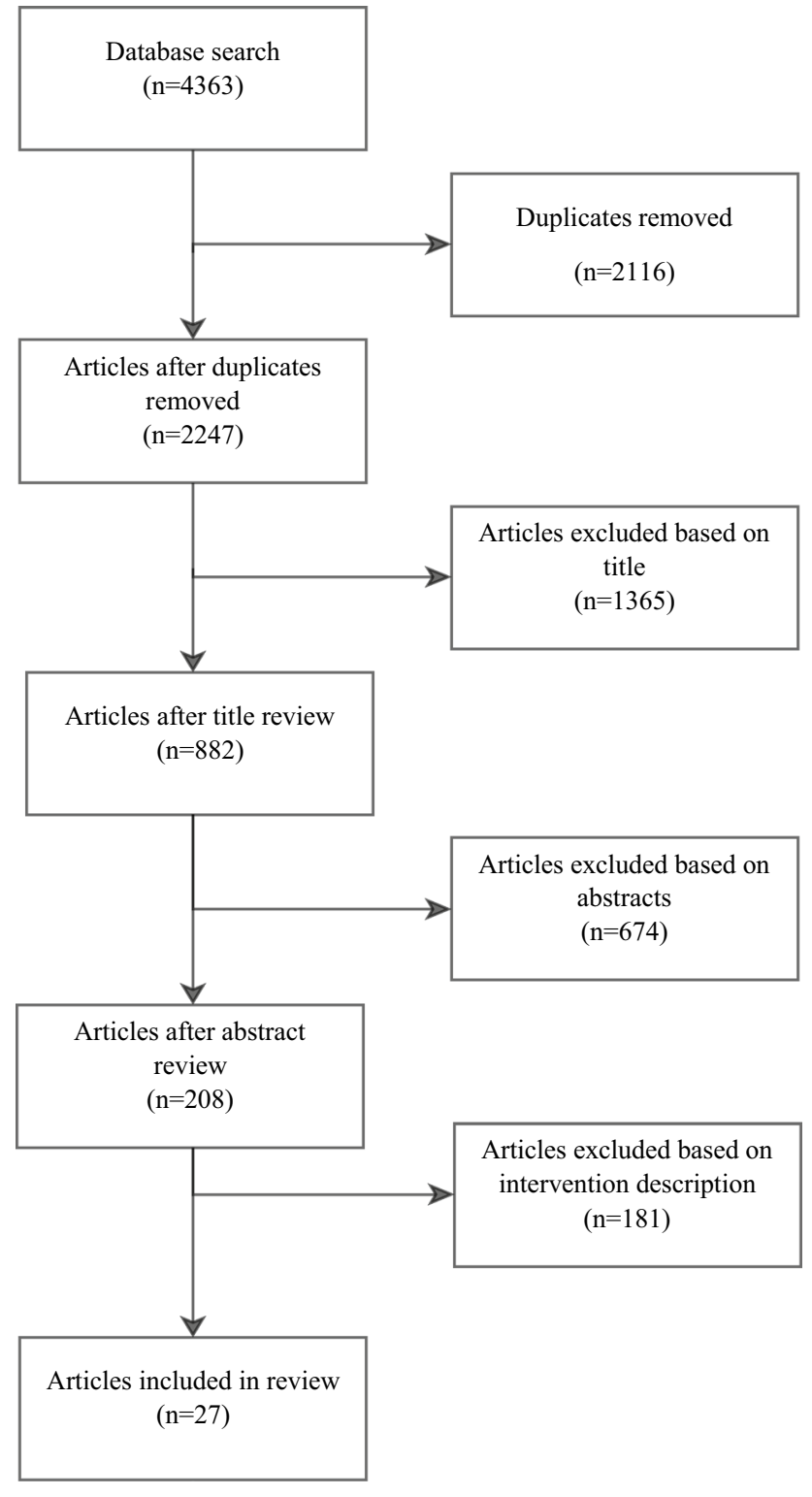

Fig. 1 Article search flowchart

review due to time and resource constraints. Ultimately, 27 studies were selected for inclusion and analysis.

\section{Charting the Data}

The second and third authors charted the 27 articles according to the following extraction fields: publication year, authors, title, country, purpose/research questions, population characteristics, sample size, study design, intervention duration and description, facilitator qualifications, comparator description, outcome measures, outcomes, and researchers' rationales for the use of arts-based MBIs (see Table 3 for a list of included articles and relevant extraction data).

\section{Results}

The analysis phase of a scoping review should include three steps: analyzing the data, reporting results, and applying meaning to the results. Analysis typically involves a descriptive numerical summary and a thematic analysis (Levac, Colquhoun, \& O’Brien, 2010).

\section{Characteristics of Arts-Based MBls}

Of the 27 studies, 10 were based in Canada, eight were based in the United States of America, and five were based in Australia. One study was from South Korea, Norway, and Kosovo respectively. One article reported on two studies, one from Australia and another from Sweden evaluating the same MBI. Studies included children/youth between the ages of 7-27 years, with the highest minimum age requirement being 16 years. Twenty-one of the MBIs were offered to boys and girls. Most of the studies targeted specific populations that included youth with chronic pain and illness, low income, placement in foster care, incarceration, learning disabilities, anxiety, eating disorders, posttraumatic stress disorder, depression, disruptive behaviors, and other mental health challenges. Six studies recruited youth from schools or the general population.

Eight studies employed solely qualitative designs. Nine of the remaining studies had primarily quantitative designs whilst also featuring qualitative methods. Six studies identified themselves as randomized controlled trials (RCTs) compared to 14 intervention trials that were non-RCTs. Eight of the non-RCT designs included control groups. Twenty-three of the studies had total sample sizes of less than 100, but one RCT included 347 participants. New programs usually require preliminary evidence of benefits before being studied more widely. Thus, many of the studies were pilot projects (Jee et al., 2015), feasibility studies (Klatt, Harpster, Browne, White, \& Case-Smith, 2013) or exploratory studies (Milligan, Badali, \& Spiroiu, 2015). Research investigating arts-based MBIs is emergent, which may account in part for the heterogeneity of the MBIs and the study designs.

Integra Mindfulness Mixed Martial Arts (MMA) (Milligan et al., 2015, 2016), Taming the Adolescent Mind (Tan \& Martin, 2013, 2015), and the Holistic Arts-Based Program (Coholic \& Eys, 2016; Coholic, Eys, \& Lougheed, 2012) were the only MBIs reported in multiple studies. Briefly, MMA aims to decrease challenging behaviors, increase self-awareness, control, and adaptability, and improve social and self-defence skills. The 20 -week program consists of weekly 1.5 -h sessions that include mindfulness, cognitive behavioral therapy (CBT), and mixed 


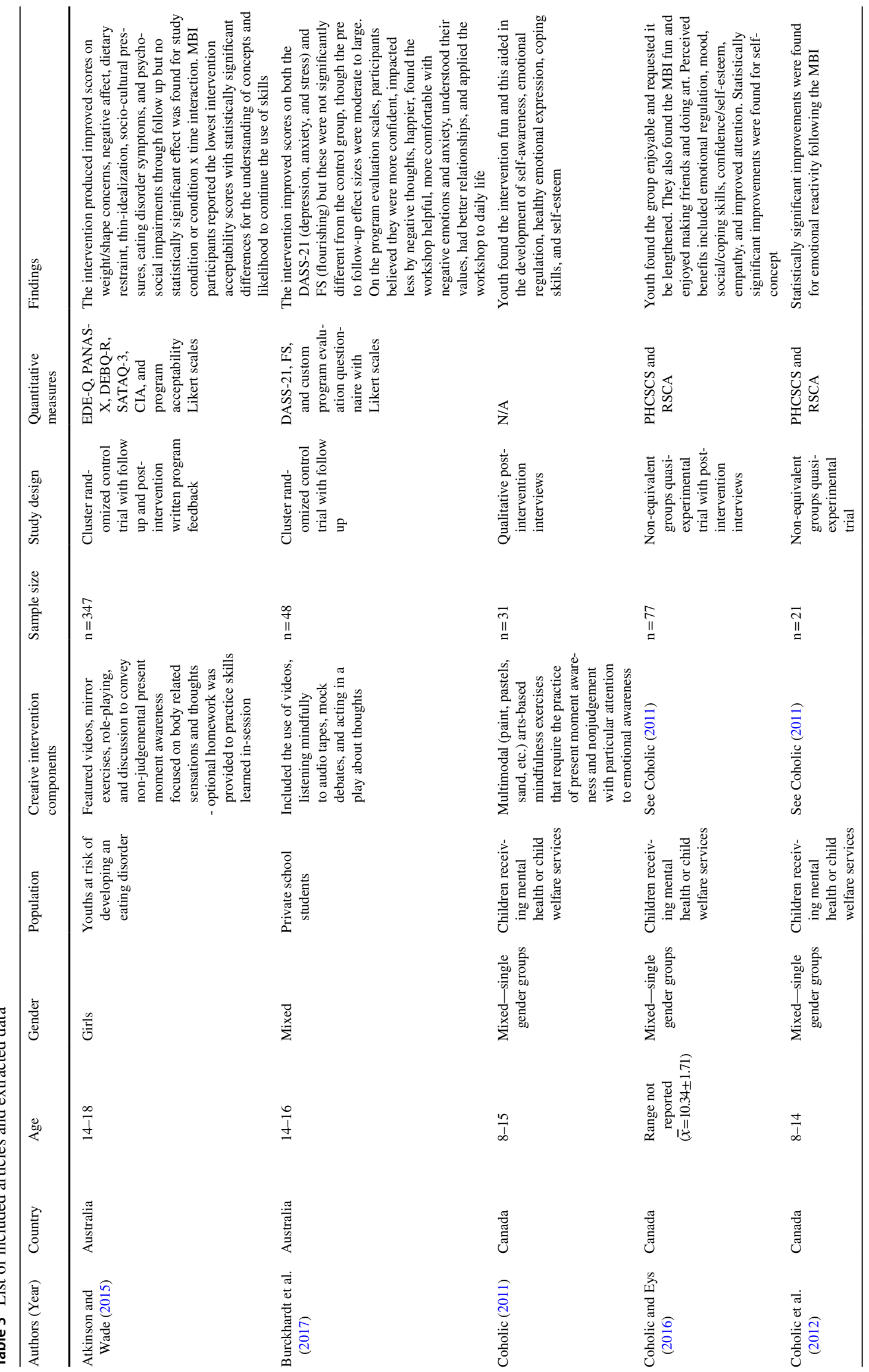




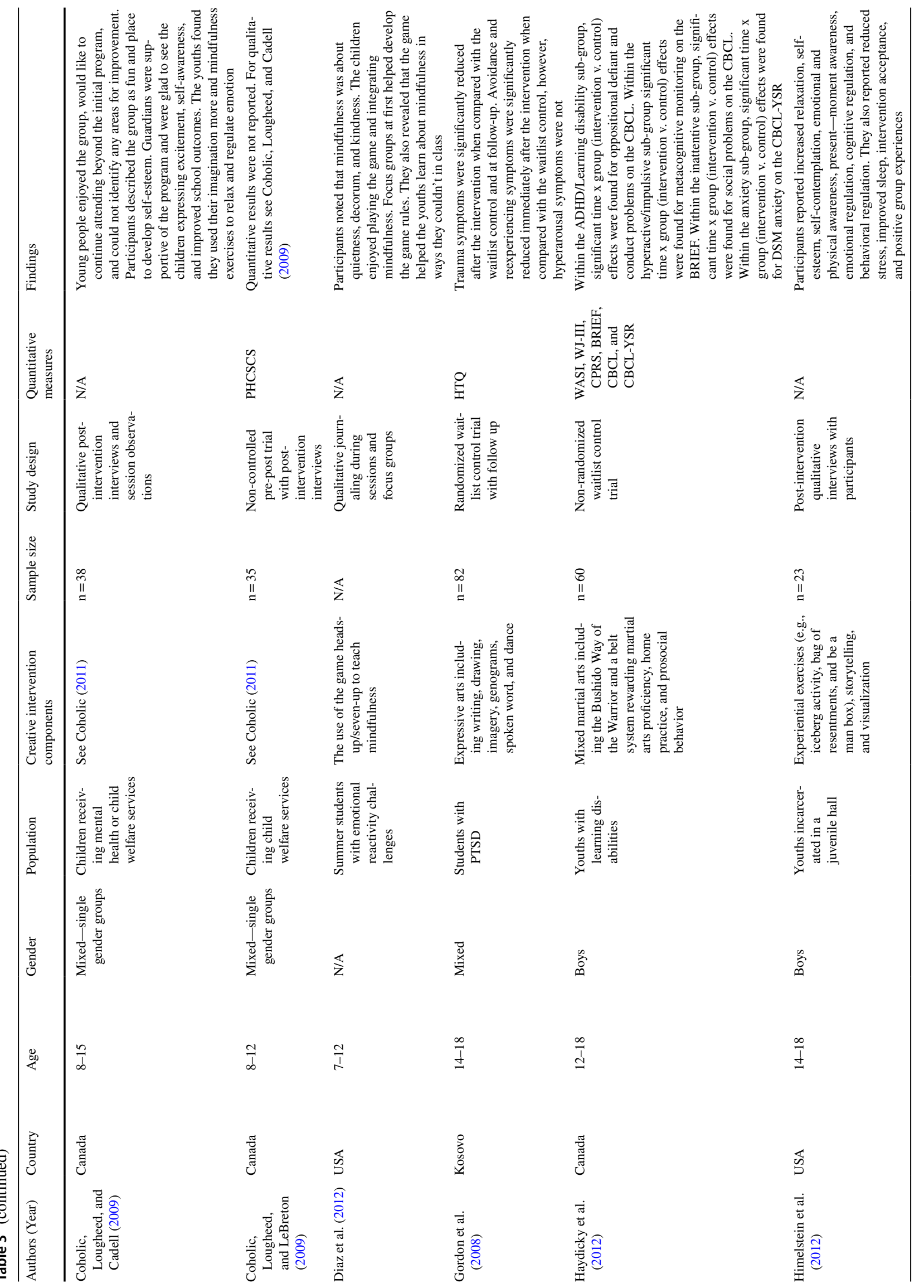




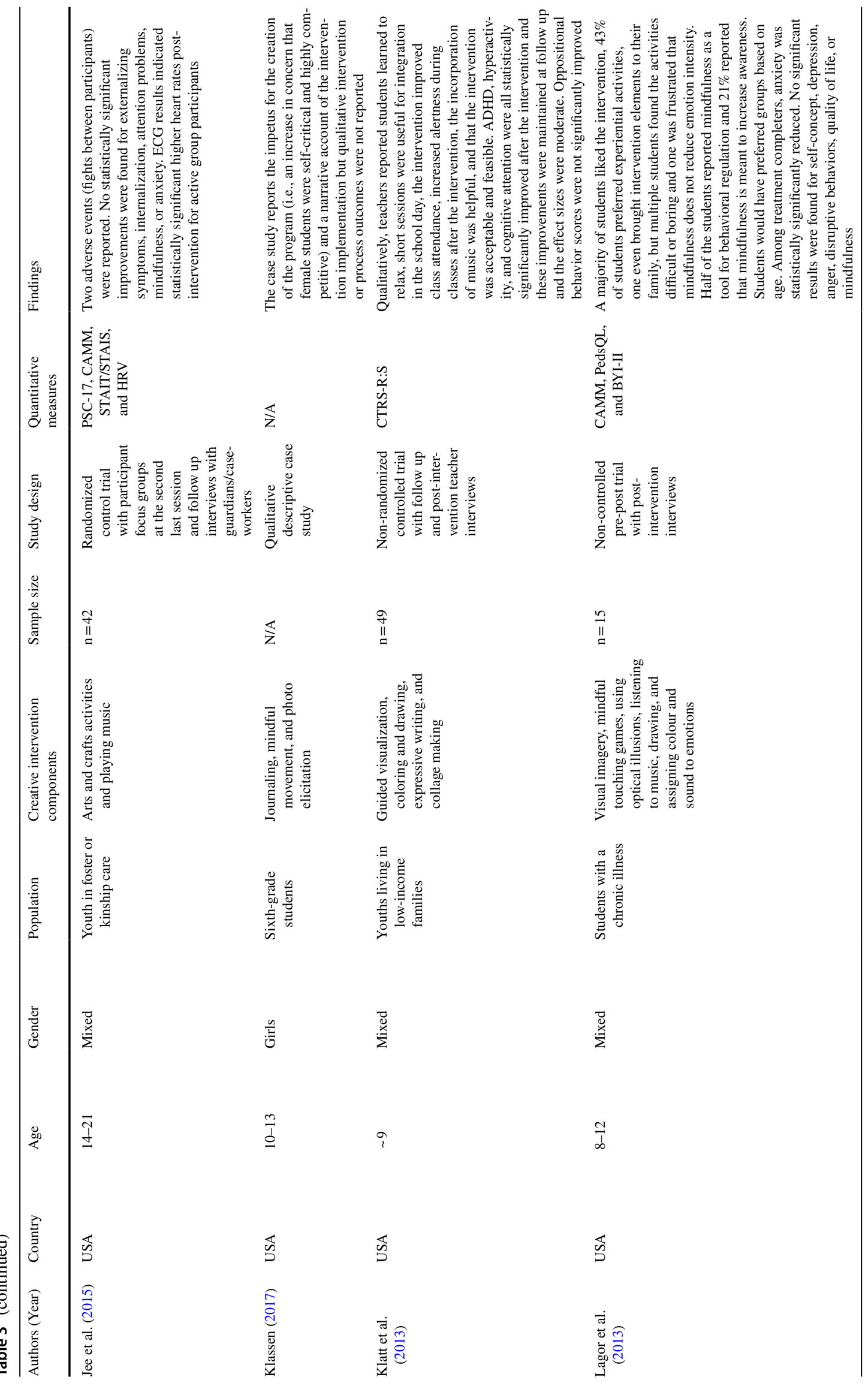




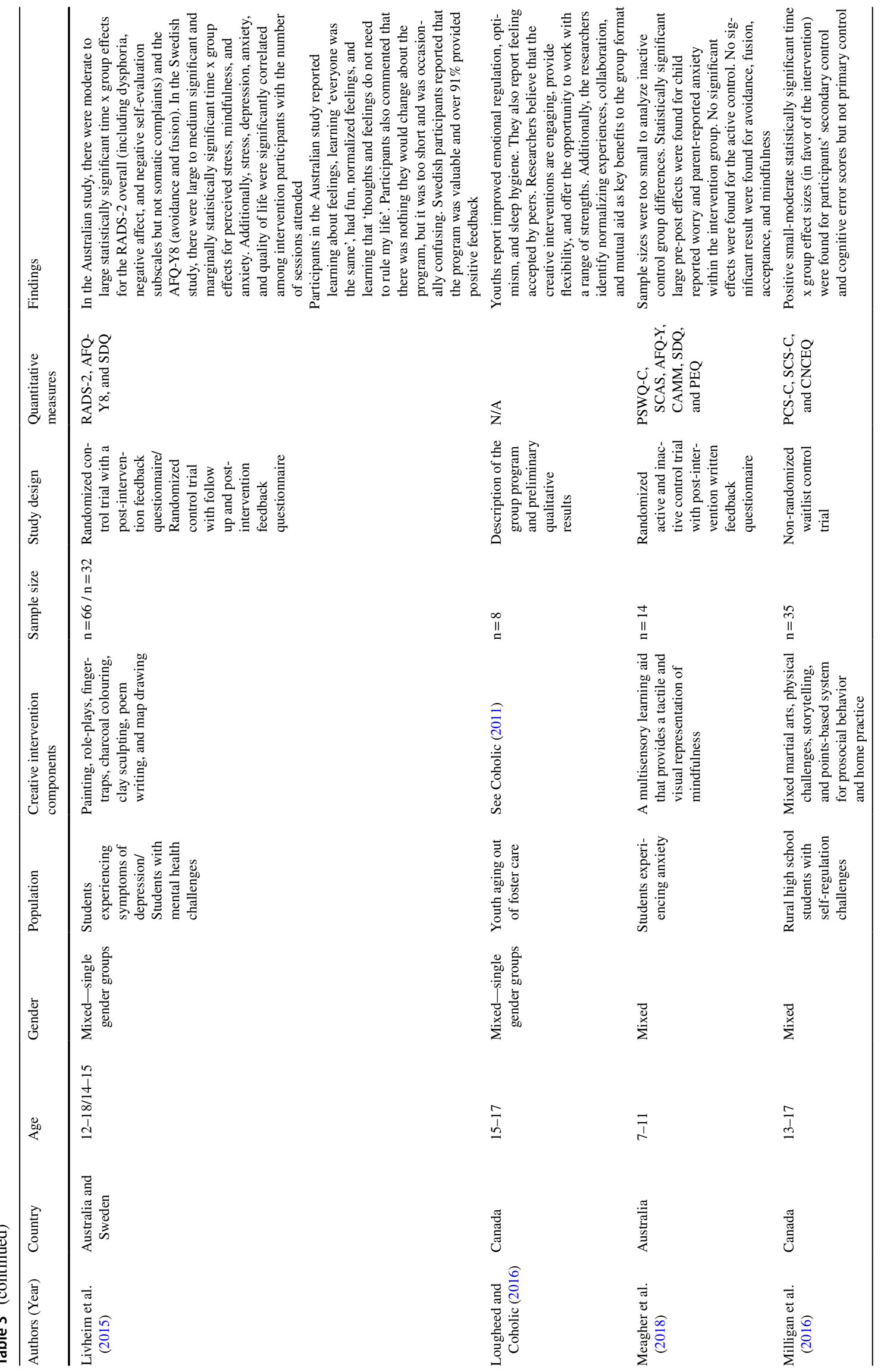




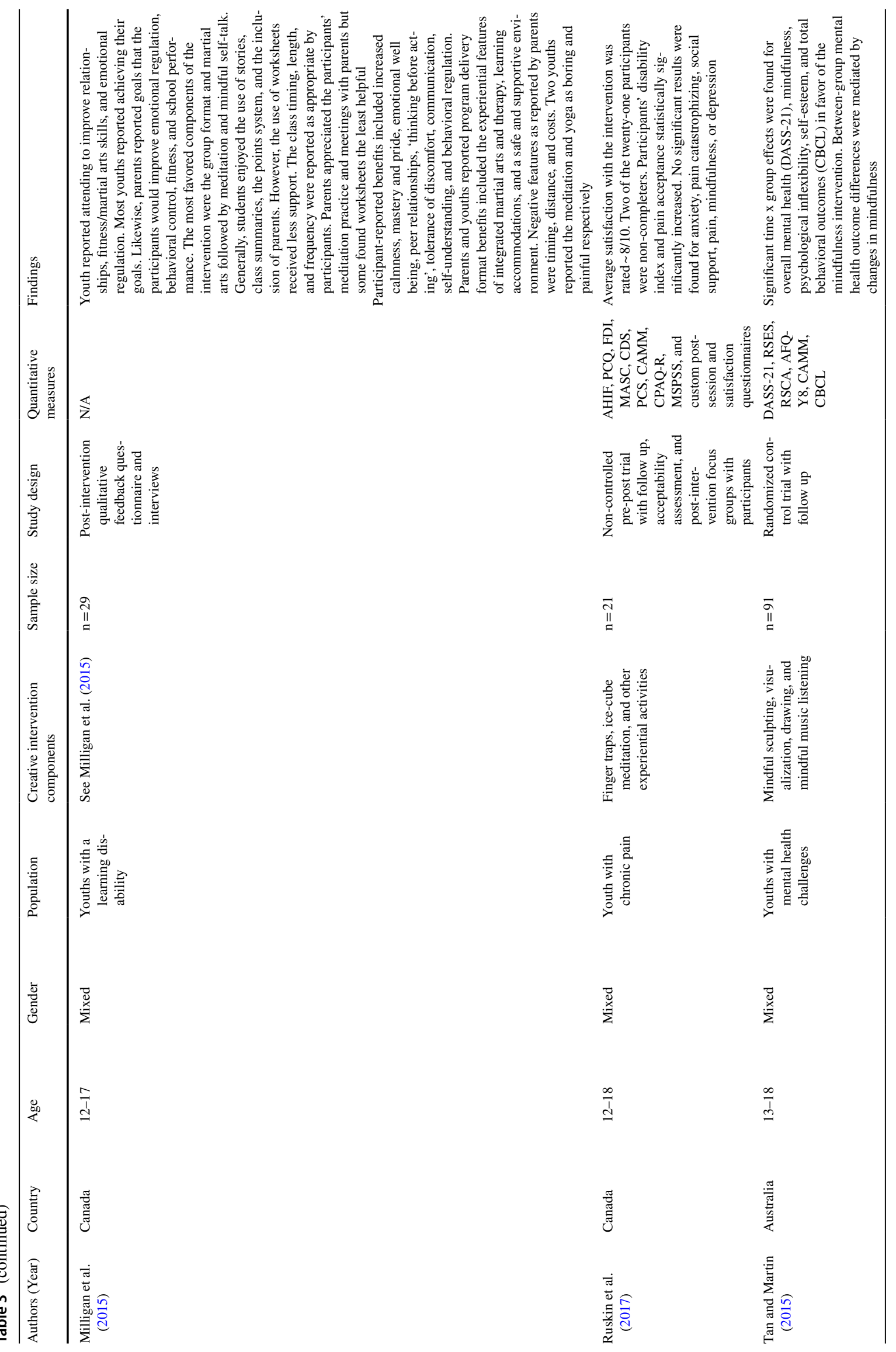




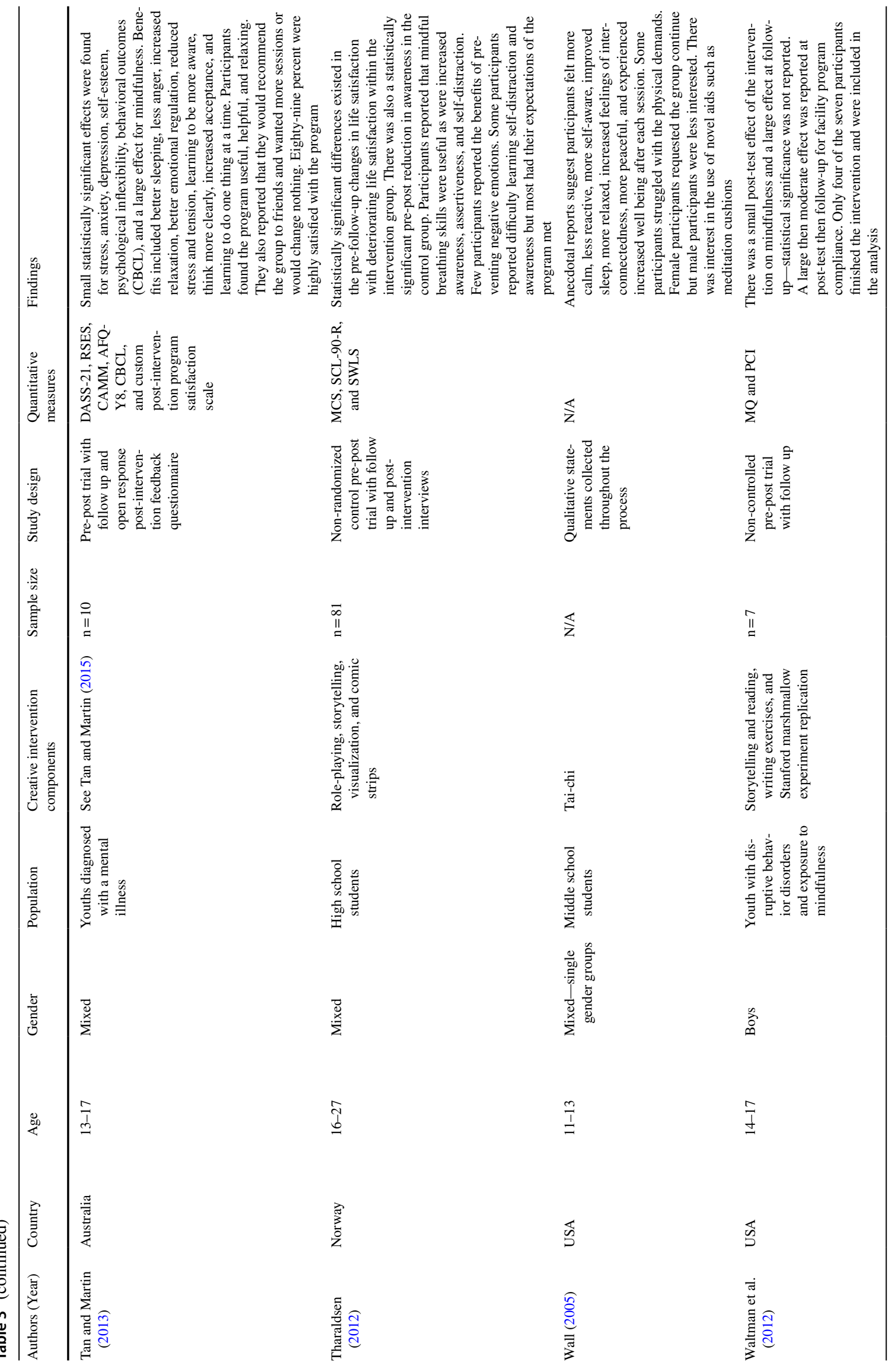




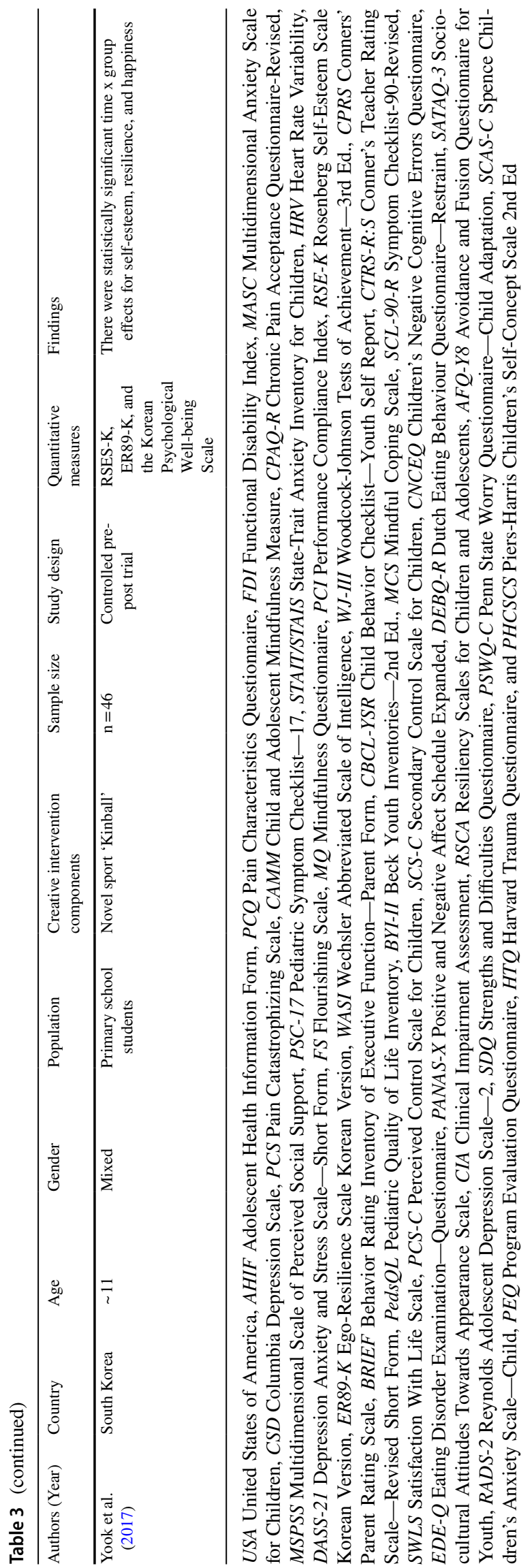

martial arts. Key mindfulness concepts emphasized are impermanence, nonjudgment, acceptance, letting go, and focusing on the moment (Haydicky, Wiener, Badali, Milligan, \& Ducharme, 2012). Taming the Adolescent Mind (Tan \& Martin, 2013) is based on the adult MBSR but delivered over 5-weeks in 1-h group sessions. Modifications to the adult MBSR include shorter meditations and a variety of activities such as mindful drawing, eating, listening to music, and sculpting given youths' need for movement and familiar activities. Program goals include mastering attention regulation, improving internal and external awareness, nonjudgmental acceptance, and learning how to be mindful. Finally, the Holistic Arts-Based Program (HAP) is a strengths-based group intervention with the following goals: teaching mindfulness in accessible and relevant ways; improving self-awareness and expression of feelings and thoughts; developing selfcompassion and empathy; and recognizing and shoring up strengths. It was developed and refined through research with marginalized children and youth, and is traditionally offered over 12 weeks in weekly 2 -h sessions (Coholic \& Eys, 2016).

\section{Rationales for an Arts-Based Approach}

While the rationales for the use of arts-based methods were not always well articulated, some rationales were connected with characteristics of the participants including that activities had to be age appropriate, and the need to engage young people who can be noncompliant, have short attention capacities and a variety of interests, possess limited verbal fluency, and struggle with abstract reasoning. Himelstein, Hastings, Shapiro, and Heery (2012) noted the ability of their MBI to engage and retain incarcerated adolescents who are a particularly difficult group to engage in helping processes. Also, Coholic (2011) argued that some marginalized youth may not have the capacities for, or interests in, learning mindfulness by way of traditional practices such as sitting meditations. Another study noted that young people reported a desire to play during MBIs (Diaz, Liehr, Curnan, Brown, \& Wall, 2012). Creative methods involving play were adopted in Diaz et al.'s (2012) work to improve retention. Similarly, Tan and Martin (2013) noted that MBIs for youths should incorporate a range of activities that involve physical activity and pastimes already familiar to adolescents (drawing, listening to music, art, etc.). Yook, Kang, and Park (2017) reported physical activity was utilized because of its many benefits for psychological health in general. Thus, mindfulness needs to be facilitated in a manner that engages youth in a strengths-based helping process that promotes success.

Other rationales were connected with the ability of arts-based methods to teach mindfulness-based practices and concepts including the processes of self-expression, 
improved understanding of feelings and thoughts, and self-compassion and non-judgement. Arts-based methods included martial arts, tai chi, theatre/drama, drawing, sculpting, painting, music, creative writing and more. For example, Klassen (2017) stated that journaling could improve participants' self-awareness, and Milligan et al. (2016) commented that interventions utilizing movement can improve a youth's ability to observe and accept distressing sensations and emotions. In our own MBI program, painting to different types of music helped participants to explore and express feelings and thoughts, and drawing oneself as a tree helped the participants to share about themselves and develop self-awareness (Coholic \& Eys, 2016). Other experiential examples included Burckhardt, Manicavasagar, Batterham, Hadzi-Pavlovic, and Shand's (2017) use of theatre to help participants practice thought diffusion, and Gordon, Staples, Blyta, Bytyqi, and Wilson's (2008) use of dance to reduce physical tension and explore emotions. Creative interventions were also used in a didactic manner such as when Ruskin et al. (2017) used finger traps to illustrate the concepts of acceptance and resistance. Meagher, Chessor, and Fogliati (2018) used a multi-sensory teaching aid to explain the transient nature of thoughts.

\section{Key Findings from the Arts-Based MBIs}

Diverse benefits were reported and included improved responses to stress and depressive symptoms (Livheim et al., 2015), increased comfort with challenging emotions (Burckhardt et al., 2017), and being able to think before acting and other metacognitive skills. For example, Haydicky et al. (2012) reported that boys with ADHD had significant improvements in parent-rated oppositional defiant problems and conduct problems. Improved self-concept (Coholic \& Eys, 2016) and feelings of confidence and happiness (Yook et al., 2017) were noted as were feelings of general wellbeing and interconnectedness (Wall, 2005).

Most of the studies were focused on specific populations and findings were related to the goals of the MBIs and characteristics of these populations. For instance, Atkinson and Wade's (2015) MBI was focused on the prevention of eating disorders. They concluded that the MBI had a positive impact on weight and shape concerns, which are relevant in eating disorder prevention. They also concluded that the girls in their study indicated a strong preference for the increased use of visual and interactive activities. Lagor, Williams, Lerner, and McClure (2013) found that their MBI reduced anxiety in chronically ill youth, and Ruskin et al. (2017) found that youth with chronic pain reported learning mindfulness helped them to cope better with their pain. Waltman, Hetrick, and Tasker (2012) studied adolescent males living in residential treatment with poor behavior control and noted that the largest self-reported change was in the ability to notice feelings without having to react to them, which is a skill particularly important for these youth. Also, there were improvements noted in trauma symptoms in youth diagnosed with Post-Traumatic Stress Disorder (Gordon et al., 2008).

Several of the studies found mixed or unexpected results. For example, one study found participants' heart rates, a measure of physiological stress, increased following the intervention (Jee et al., 2015). This was attributed in part to the population's (traumatized youth-in-care) possible desensitization to stress, and the reality that practicing mindfulness can raise awareness of difficult emotions. Tharaldsen (2012) explained that contradictory findings are valuable as they encourage re-examination of conceptual frameworks. They also pointed out that an increased awareness of difficult feelings could lead to participants feeling worse than at the beginning of an intervention. Thus, they concluded that mixed methods research is most helpful as different types of data can help us understand research results in a more thorough manner.

\section{Consultation with Youth}

An optional step in a scoping review is consultation with appropriate stakeholders (Levac et al., 2010). We decided to invite youth (aged 11-17 years) who had recently participated in HAP groups to take part in a group discussion regarding our preliminary findings from the scoping review. Given these youths' recent experiences in an arts-based mindfulness program, we thought it would be interesting to elicit their viewpoints regarding what we found in the literature regarding rationales for using arts-based methods. This also reflected our commitment to including youth in our research processes in meaningful ways. Six youth from three different HAP groups attended an hour-long meeting where we provided pizza and an opportunity to engage in some arts-based activities as incentives. At the beginning of the discussion, we asked the youth to think about their recent experiences in HAP and to compare these with the following rationales for using arts-based methods in MBIs, which were written on a white board: (1) engaging and interesting, (2) promote the development of self-awareness, (3) help participants pay attention, (4) help participants to stay with uncomfortable feelings, (5) address retention, (6) aid self-expression, and (7) address youth's need for movement. Through our group discussion, we encouraged the youth to identify which of these seven rationales most resonated with them. They identified three factors that were most reflective of their own experiences in HAP: (1) arts-based methods were engaging/interesting and "not boring" (2) arts-based methods helped them pay attention and focus, and address their "wandering minds" and, (3) arts-based methods helped them express themselves. They added that the arts-based methods were "fun and different" and that they have been 
able to carry on with some of the activities at home. They also appreciated the arts-based approaches to breathing, which helped them learn how to focus on their breath and meditate.

\section{Discussion}

This scoping review examined why and how arts-based methods were used in MBIs. A variety of approaches were studied with diverse youth populations with a variety of challenges. Because arts-based MBIs were often developed for a specific population, a good number of the studies were pilot projects investigating the suitability and benefits of the MBIs. Rationales for the use of arts-based methods included both the characteristics of children and youth, and benefits of the methods themselves. In our consultation with a small group of youth, they confirmed that arts-based methods were engaging, interesting, fun, and helpful. Participating in the MBIs helped the youth develop capacities such as self-awareness and non-judgment, and abilities to cope with challenges such as poor mood and emotion regulation.

There are sound rationales for using arts-based methods based both on participant characteristics and the benefits of creative approaches. One of the main reasons identified for the use of arts-based approaches was the ability of these methods to engage hard to reach youth and/or youth with challenging problems such as chronic pain or eating disorders. Thus, many of the creative MBIs were developed for specific youth populations including marginalized youth, youth with chronic pain, incarcerated youth, and youth with learning disabilities. The benefits reported in the studies indicated that mindfulness-based practices and concepts can be taught by way of arts-based methods, and can have benefits for youth who may not engage in a more traditional MBI such as MBSR. When working with youth, it is important to enable them to engage with methods that they find enjoyable, meaningful, and helpful for self-expression and learning. We should not diminish the importance of creativity, fun, and play for children and youth learning new skills and concepts.

In fact, arts-based group modalities have a long history within helping practices with children and youth (Kelly \& Doherty, 2017). In particular, they have been used extensively in non-deliberative social group work practice. Nondeliberative practice recognizes that there are multiple avenues for self-expression that do not rely on verbalization. Instead, the arts and creative processes act as analogs for situations and challenges that youths face outside of the group (Lang, 2016). Others have found that arts-based methods help people express their thoughts and feelings that would otherwise remain unidentified (Sinding, Warren, \& Paton, 2014). Indeed, youths with communication challenges may find arts-based modalities more accessible and feasible than the high level of verbalization and cognition required for more traditional talk-based interventions. Furthermore, group-based arts and crafts have been identified as a source of enjoyment for marginalized youth who live in unstable environments (Punch, 2002). Thus, they are highly engaging and can become a refuge for children and youth. Moreover, they can be culturally competent practices. For example, crafting has been recognized as a holistic intervention appropriate for use with Indigenous peoples living in Canada (Archibald \& Dewar, 2010).

Given the promising benefits of MBIs and arts-based interventions with youths, a combined approach may make more sense especially for children and youth dealing with serious problems. The practices may work synergistically, for instance, the art-making process provides children an in vivo opportunity to not only explore analogous situations but to additionally practice mindful awareness and acceptance. Mindfulness is a complicated concept to teach didactically; it may require experiential activities such as those found in arts-based social work groups (Thompson \& Gauntlett-Gilbert, 2008). Arts also provide youths a unique method of practicing and embodying mindfulness that does not rely on sitting meditation. The frontal lobe of young people is generally in the process of developing and their executive functioning skills are limited (Greenberg, 2006). A lack of attention regulation may intensify the difficulty of sitting meditation especially for marginalized youths who are also dealing with challenging life situations. Creative arts-based meditation involving audio tracks and sculpting, actively engage multiple sensory inputs including visual, auditory, and tactile systems. Importantly, by engaging youths in enjoyable and successful activities, they can learn about and practice mindfulness-based practices and concepts.

\section{Research Directions and Implications for Practitioners}

Based on reported results and the needs/developmental stages of children and youth, practitioners and researchers should be encouraged to facilitate and study MBIs that focus on arts-based approaches. The study of arts-based MBIs is emergent, which may account in part for their lack of prominence in this field and the diversity of approaches being developed and studied. We agree that there is a need for MBIs that are youth-centered in their design and shaped by feedback from youth as opposed to adaptations predetermined to be appropriate for use with young people (Diaz et al., 2012). Also, authors writing about arts-based MBIs should more thoroughly describe the synthesis of practice wisdom, research, and feedback used in the design and delivery of their MBI. Generating a sufficient evidence base is 
vital for the dissemination and study of MBIs. Thus, we encourage researchers and practitioners to draw on existent arts-based MBIs that show promising benefits for children and youth rather than develop new programs.

It may be more complex and challenging to offer creative MBIs as researchers and facilitators require training not just in mindfulness but in arts-based approaches as well. For instance, one could not facilitate the MMA program without having gained advanced belts in various forms of martial arts (Milligan et al., 2015). However, there are ways to address the need for specific facilitator qualifications. As Haydicky et al. (2012) explained, volunteers with martial arts expertise and advanced students of MMA could assist qualified facilitators. We have previously encouraged helping practitioners without specialized degrees in creative therapies to offer arts-based methods as part of their practices because arts-based methods are used as tools for engagement and self-expression, and teaching concepts and practices (Coholic, Lougheed, \& Cadell, 2009; Coholic, Lougheed, \& LeBreton, 2009). Helping practitioners can access the plethora of resources in arts-based approaches in order to gain confidence in incorporating these practices into their interventions (Carey, 2006; Malchiodi, 2007).

In line with other researchers, we have found that feedback from youth indicated that the arts-based nature of our MBI was a key component in their engagement and appreciation of the program (Coholic \& Eys, 2016). Thus, learning and practicing mindfulness, in and of itself, is likely not the only mechanism of change. It is quite possible that the effectiveness of a program might be due to a combination of factors including group work, mindfulness practice, and other factors such as specific cultural practices and/or an arts-based approach to learning mindfulness. As research in this field develops, it might become more evident that some arts-based methods work more effectively for specific issues or youth populations. For instance, we have often struggled with engaging male youth over the age of 15 years in HAP. Perhaps for these young men, learning mindfulness via movement such as karate or outdoor activities would be more appealing and relevant. In general, we need to better understand what methods work for whom, and all of the factors contributing to change as a result of having participated in an MBI.

\section{Limitations}

The literature in the area of arts-based MBIs with children and youth includes a wide diversity of programs of varying lengths facilitated with diverse groups of youth. In future reviews, researchers should focus on specific populations and challenges, which could develop our understanding of effective approaches for particular groups of youth. This would also make the review process more manageable and in-depth. For example, Simpson, Mercer, Simpson, Lawrence, and Wyke (2018) conducted a scoping review that explores MBIs for young offenders. Also, we lacked the time and resources to include a review of dissertations, which may be where some novel approaches are first described and studied. We note that a scoping review is very time consuming and additional human resources would have helped us finalize the results in a timely manner. Also, in our review, it was sometimes challenging for us to understand if an MBI could be considered arts-based, especially since many of these MBIs were not described with enough detail. Thus, there is a chance that we eliminated some MBIs because the program was not described in sufficient detail for us to assess how arts-based approaches were used.

Finally, our consultation occurred with a small group of youth. We would have liked to recruit more youth to participate in multiple group discussions but time constraints and the time of year (it was summer when many youth were unavailable) limited the depth and scope of our process. In the future, we would also like to consult with practitioners/ researchers facilitating and studying arts-based MBIs. We would have to conduct this consultation using an on-line video/audio platform given our physical location in a smaller city far from larger urban centres, and the lack of similarly engaged professionals in our community. In conclusion, we note that the attention paid to testing arts-based MBIs has not been robust. Given the known benefits of arts-based methods for children and youth, we believe that more focus should be paid to these practices and how mindfulness-based concepts and skills can be taught using these methods. In this manner, more youth may have the chance to benefit from participating in MBIs.

Acknowledgement We acknowledge the assistance of Mr. Ashley Thomson, Librarian at Laurentian University. The research described in this paper was supported in part by funding from the Social Sciences and Humanities Research Council of Canada.

\section{Compliance with Ethical Standards}

Conflict of interest The authors declare that they have no conflict of interest.

Open Access This article is licensed under a Creative Commons Attribution 4.0 International License, which permits use, sharing, adaptation, distribution and reproduction in any medium or format, as long as you give appropriate credit to the original author(s) and the source, provide a link to the Creative Commons licence, and indicate if changes were made. The images or other third party material in this article are included in the article's Creative Commons licence, unless indicated otherwise in a credit line to the material. If material is not included in the article's Creative Commons licence and your intended use is not permitted by statutory regulation or exceeds the permitted use, you will need to obtain permission directly from the copyright holder. To view a copy of this licence, visit http://creativecommons.org/licenses/by/4.0/. 


\section{References}

Alsubaie, M., Abbott, R., Dunn, B., Dickens, C., Frieda Keil, T., Henley, W., et al. (2017). Mechanisms of action in mindfulness-based cognitive therapy (MBCT) and mindfulness-based stress reduction (MBSR) in people with physical and/or psychological conditions: A systematic review. Clinical Psychology Review, 55, 74-91. https ://doi.org/10.1016/j.cpr.2017.04.008.

Archibald, L., \& Dewar, J. (2010). Creative arts, culture, and healing: Building an evidence base. Pimatisiwin, 8(3), 1-25.

Arksey, H., \& O’Malley, L. (2005). Scoping studies: Towards a methodological framework. International Journal of Social Research Methodology, 8, 19-32. https://doi.org/10.1080/1364557032 000119616.

Atkinson, M. J., \& Wade, T. D. (2015). Mindfulness-based prevention for eating disorders: A school-based cluster randomized controlled study: Mindfulness-based eating disorder prevention. International Journal of Eating Disorders, 48, 1024-1037. https ://doi.org/10.1002/eat.22416.

Bajaj, B., \& Pande, N. (2016). Mediating role of resilience in the impact of mindfulness on life satisfaction and affect as indices of subjective well-being. Personality and Individual Differences, 93, 63-67. https://doi.org/10.1016/j.paid.2015.09.005.

Borquist-Conlon, D., Maynard, B., Esposito Brendel, K., \& Farina, A. (2017). Mindfulness-based interventions for youth with anxiety: A systematic review and meta-analysis. Research on Social Work Practice, 29(2), 1-11. https://doi.org/10.1177/10497 31516684961.

Burckhardt, R., Manicavasagar, V., Batterham, P., Hadzi-Pavlovic, D., \& Shand, F. (2017). Acceptance and commitment therapy universal prevention program for adolescents: A feasibility study. Child and Adolescent Psychiatry and Mental Health, 11, 27. https://doi.org/10.1186/s13034-017-0164-5.

Carey, L. (Ed.). (2006). Expressive and creative arts methods for trauma survivors. London, UK: Jessica Kingsley Publishers.

Chambers, R., Gullone, E., \& Allen, N. B. (2009). Mindful emotion regulation: An integrative review. Clinical Psychology Review, 29, 560-572. https://doi.org/10.1016/j.cpr.2009.06.005.

Chiesa, A., Fazia, T., Bernardinelli, L., \& Morandi, G. (2017). Citation patterns and trends of systematic reviews about mindfulness. Complementary Therapies in Clinical Practice, 28, 26-37. https://doi.org/10.1016/j.ctcp.2017.04.006.

Coholic, D. (2011). Exploring the feasibility and benefits of artsbased mindfulness-based practices with young people in need: Aiming to improve aspects of self-awareness and resilience. Child and Youth Care Forum, 40, 303-317. https://doi. org/10.1007/s10566-010-9139-x.

Coholic, D., \& Eys, M. (2016). Benefits of an arts-based mindfulness group intervention for vulnerable children. Child \& Adolescent Social Work Journal, 33, 1-13. https://doi.org/10.1007/s1056 0-015-0431-3.

Coholic, D., Eys, M., \& Lougheed, S. (2012). Investigating the effectiveness of an arts-based and mindfulness-based group program for the improvement of resilience in children in need. Journal of Child and Family Studies, 21, 833-844. https://doi.org/10.1007/ s10826-011-9544-2.

Coholic, D., Lougheed, S., \& Cadell, S. (2009a). Exploring the helpfulness of arts-based methods with children living in foster care. Traumatology, 15, 64-71. https://doi.org/10.1177/1534765609 341590.

Coholic, D., Lougheed, S., \& LeBreton, J. (2009b). The helpfulness of holistic arts-based group work with children living in foster care. Social Work with Groups, 32, 29-46. https://doi. org/10.1080/01609510802290966.
Coholic, D., Schinke, R., Oghene, O., Dano, K., Jago, M., McAlister, H., et al. (2019). Arts-based interventions for youth with mental health challenges. Journal of Social Work. https://doi. org/10.1177/1468017319828864.

Davis, K., Drey, N., \& Gould, D. (2009). What are scoping studies? A review of the nursing literature. International Journal of Nursing Studies, 46, 1386-1400. https://doi.org/10.1016/j. ijnurstu.2009.02.010.

Diaz, N., Liehr, P., Curnan, L., Brown, J. L. A., \& Wall, K. (2012). Playing games: Listening to the voices of children to tailor a mindfulness intervention. Children, Youth and Environments, 22, 273-285. https://doi.org/10.7721/chilyoutenvi.22.2.0273.

Fjorback, L., Arendt, M., Ornbol, E., Fink, P., \& Walach, H. (2011). Mindfulness-based stress reduction and mindfulness-based cognitive therapy: A systematic review of randomized controlled trials. Acta Psychiatrica Scand., 124, 102-119. https://doi.org/ 10.1111/j.1600-0447.2011.01704.x.

Gordon, J. S., Staples, J. K., Blyta, A., Bytyqi, M., \& Wilson, A. T. (2008). Treatment of posttraumatic stress disorder in postwar Kosovar adolescents using mind-body skills groups: A randomized controlled trial. Journal of Clinical Psychiatry, 69, 1469-1476. https://doi.org/10.4088/jcp.v69n0915.

Grant, M. J., \& Booth, A. (2009). A typology of reviews: An analysis of 14 review types and associated methodologies. Health Information and Libraries Journal, 26, 91-108. https://doi.org/10.11 11/j.1471-1842.2009.00848.x.

Greenberg, M. T. (2006). Promoting resilience in children and youth. Annals of the New York Academy of Sciences, 1094, 139-150. https://doi.org/10.1196/annals.1376.01.

Harnett, P. H., \& Dawe, S. (2012). Review: The contribution of mindfulness-based therapies for children and families and proposed conceptual integration. Child and Adolescent Mental Health, 17, 195-208. https://doi.org/10.1111/j.1475-3588.2011.00643.x.

Haydicky, J., Wiener, J., Badali, P., Milligan, K., \& Ducharme, J. (2012). Evaluation of a mindfulness-based intervention for adolescents with learning disabilities and co-occurring ADHD and anxiety. Mindfulness, 3, 151-164. https://doi.org/10.1007/s1267 1-012-0089-2.

Hayes, S., Strosahl, K., \& Wilson, K. (1999). Acceptance and commitment therapy: An experiential approach to behavior change. New York: Guilford.

Himelstein, S., Hastings, A., Shapiro, S., \& Heery, M. (2012). A qualitative investigation of the experience of a mindulnessbased intervention with incarcerated adolescents. Child and Adolescent Mental Health, 17, 231-237. https://doi.org/10.111 1/j.1475-3588.2011.00647.x.

Horesh, D., \& Gordon, I. (2018). Mindfulness-based therapy for traumatized adolescents: An underutilized, understudied intervention. Journal of Loss and Trauma, 23, 627-638. https://doi. org/10.1080/15325024.2018.1438047.

Jee, S. H., Couderc, J., Swanson, D., Gallegos, A., Hilliard, C., Blumkin, A., ... Heinert, S. (2015). A pilot randomized trial teaching mindfulness-based stress reduction to traumatized youth in foster care. Complementary Therapies in Clinical Practice, 21, 201-209. https://doi.org/10.1016/j.ctcp.2015.06.007

Kabat-Zinn, J. (1990). Full catastrophe living: Using the wisdom of your body and mind to face stress, pain and illness. New York: Delta.

Kabat-Zinn, J. (2003). Mindfulness-based interventions in context: Past, present, and future. Clinical Psychology: Science and Practice, 10, 144-156. https://doi.org/10.1093/clipsy.bpg016.

Kelly, B. L., \& Doherty, L. (2017). A historical overview of art and music-based activities in social work with groups: Nondeliberative practice and engaging young people's strengths. Social Work with Groups, 40, 187-201. https://doi.org/10.1080/01609 513.2015.1091700. 
Klassen, S. (2017). Free to be: Developing a mindfulness-based eating disorder prevention program for preteens. Journal of Child and Adolescent Counseling, 3, 75-87. https://doi.org/10.1080/23727 810.2017.1294918.

Klatt, M., Buckworth, J., \& Malarkey, W. (2009). Effects of lowdose mindfulness-based stress reduction (MBSR-ld) on working adults. Health Education \& Behavior, 36, 601-614. https://doi. org/10.1177/1090198108317627.

Klatt, M., Harpster, K., Browne, E., White, S., \& Case-Smith, J. (2013). Feasibility and preliminary outcomes for move-into-learning: An arts-based mindfulness classroom intervention. The Journal of Positive Psychology, 8, 233-241. https://doi.org/10.1080/17439 760.2013.779011.

Lagor, A., Williams, D. J., Lerner, J., \& McClure, K. (2013). Lessons learned from a mindfulness-based intervention with chronically ill youth. Clinical Practice in Pediatric Psychology, 1, 146-158. https://doi.org/10.1037/cpp0000015.

Lang, N. (2016). Nondeliberative forms of practice in social work: Artful, actional, analogic. Social Work with Groups, 39, 97-117. https://doi.org/10.1080/01609513.2015.1047701.

Levac, D., Colquhoun, H., \& O'Brien, K. (2010). Scoping studies: Advancing the methodology. Implementation Science, 5, 1-9. https://doi.org/10.11186/1748-5908-5-69.

Livheim, F., Hayes, L., Ghaderi, A., Magnusdottir, T., Hogfeldt, A., Rowse, J., ... Tengstrom, A. (2015). The effectiveness of acceptance and commitment therapy for adolescent mental health: Swedish and Australian pilot outcomes. Journal of Child and Family Studies, 24, 1016-1030. https://doi.org/10.1007/s 1082 6-014-9912-9.

Lougheed, S., \& Coholic, D. (2016). Arts-based mindfulness group work with youth aging out of foster care. Social Work with Groups, 41, 165-178. https://doi.org/10.1080/01609513.2016.1258626.

Malchiodi, C. (2007). The art therapy sourcebook (2nd ed.). New York, NY: McGraw-Hill.

Meagher, R., Chessor, D., \& Fogliati, V. (2018). Treatment of pathological worry in children with acceptance-based behavioral therapy and a multisensory learning aide: A pilot study: Acceptance-based anxiety treatment for children. Australian Psychologist, 53, 134-143. https://doi.org/10.1111/ap.12288.

Milligan, K., Badali, P., \& Spiroiu, F. (2015). Using integra mindfulness martial arts to address self-regulation challenges in youth with learning disabilities: A qualitative exploration. Journal of Child and Family Studies, 24, 562-575. https://doi.org/10.1007/ s10826-013-9868-1.

Milligan, K., Irwin, A., Wolfe-Miscio, M., Hamilton, L., Mintz, L., Cox, M., ...Phillips, M., (2016) Mindfulness enhances use of secondary control strategies in high school students at risk for mental health challenges. Mindfulness, 7, 219-227 https://doi. org/10.1007/s12671-015-0466-8

Perry-Parrish, C., Copeland-Linder, N., Webb, L., Shields, A. H., \& Sibinga, E. (2016). Improving self-regulation in adolescents: Current evidence for the role of mindfulness-based cognitive therapy. Adolescent Health, Medicine and Therapeutics, 7, 101-108. https://doi.org/10.2147/AHMT.S65820.

Pham, M., Rajic, A., Greig, J., Sargeant, J., Papadopoulos, A., \& McEwen, S. (2014). A scoping review of scoping reviews: Advancing the approach and enhancing the consistency. Research Synthesis Methods, 5, 371-385. https://doi. org/10.1002/jrsm.1123.

Punch, S. (2002). Research with children: The same or different from research with adults? Childhood, 9, 321-341. https://doi. org/10.1177/0907568202009003005.

Ruskin, D., Gagnon, M., Kohut, S., Stinson, J., \& Walker, K. (2017). A mindfulness program adapted for adolescents with chronic pain:
Feasibility, acceptability, and initial outcomes. The Clinical Journal of Pain, 33, 1019-1029. https://doi.org/10.1097/AJP.00000 00000000490

Segal, Z., Williams, J., \& Teasdale, J. (2002). Mindfulness-based cognitive therapy for depression: A new approach to preventing relapse. New York: Guilford Press.

Simpson, S., Mercer, S., Simpson, R., Lawrence, M., \& Wyke, S. (2018). Mindfulness-based interventions for young offenders: A scoping review. Mindfulness, 9, 1330-1343. https://doi. org/10.1007/s12671-018-0892-5.

Sinding, C., Warren, R., \& Paton, C. (2014). Social work and the arts: Images at the intersection. Qualitative Social Work, 13, 187-202. https://doi.org/10.1177/1473325012464384.

Tan, L., \& Martin, G. (2013). Taming the adolescent mind: Preliminary report of a mindfulness-based psychological intervention for adolescents with clinical heterogeneous mental health diagnoses. Clinical Child Psychology and Psychiatry, 18, 300-312. https:// doi.org/10.1177/1359104512455182.

Tan, L., \& Martin, G. (2015). Taming the adolescent mind: A randomised controlled trial examining clinical efficacy of an adolescent mindfulness-based group programme. Child and Adolescent Mental Health, 20, 49-55. https://doi.org/10.1111/camh.12057.

Tharaldsen, K. (2012). Mindful coping for adolescents: Beneficial or confusing. Advances in School Mental Health Promotion, 5, 105-124. https://doi.org/10.1080/1754730X.2012.691814.

Thompson, M., \& Gauntlett-Gilbert, J. (2008). Mindfulness with children and adolescents: Effective clinical application. Clinical Child Psychology \& Psychiatry, 13, 396-408. https://doi. org/10.1177/1359104508090603.

Van Vliet, K. J., Foskett, A., Williams, J., Singhal, A., Dolcos, F., \& Vohra, S. (2017). Impact of a mindfulness-based stress reduction program from the perspective of adolescents with serious mental health concerns. Child and Adolescent Mental Health, 22, 16-22. https://doi.org/10.1111/camh.12170.

Vollestad, J., Birkeland Nielsen, M., \& Hostmark Nielsen, G. (2012). Mindfulness- and acceptance-based interventions for anxiety disorders: A systematic review and meta-analysis. British Journal of Clinical Psychology, 51, 239-260. https://doi.org/10.111 1/j.2044-8260.2011.02024.x.

Wall, R. B. (2005). Tai chi and mindfulness-based stress reduction in a Boston public middle school. Journal of Pediatric Health Care, 19, 230-237. https://doi.org/10.1016/j.pedhc.2005.02.006.

Waltman, S., Hetrick, H., \& Tasker, T. (2012). Designing, implementing, and evaluating a group therapy for underserved populations. Residential Treatment for Children \& Youth, 29, 305-323. https ://doi.org/10.1080/0886571x.2012.725374.

Yook, Y. S., Kang, S. J., \& Park, I. (2017). Effects of physical activity intervention combining a new sport and mindfulness yoga on psychological characteristics in adolescents. International Journal of Sport and Exercise Psychology, 15, 109-117. https://doi. org/10.1080/1612197X.2015.1069878.

Zenner, C., Herrnleben-Kurz, S., \& Walach, H. (2014). Mindfulnessbased interventions in schools: A systematic review and metaanalysis. Frontiers in Psychology. https://doi.org/10.3389/fpsyg .2014 .00603 .

Publisher's Note Springer Nature remains neutral with regard to jurisdictional claims in published maps and institutional affiliations. 